known as tricoepithiloma [2-4]. The pathophysiology of this cyst formation is suggested to be due to a localised reaction intended to wall off excess extracellular lysosomal enzymes found in tissues in these patients. The dermatological manifestation in our baby was presence of excess skin folds and is distinct from those previously reported.

\section{References}

1. Tricot L, Yahiaoui Y, Teixeira L, et al. End-stage renal failure in Lowe syndrome. Nephrology, Dialysis, Transplantation 2003; 18: 1923-5.

2. Nandedkar MA, Minus H. Eruptive vellus hair cysts in a patient with Lowe syndrome. Pediatric Dermatology 2004; 21: 54-7.

3. Batirbaygil Y, Turgut M. Lowe syndrome: case report. The Journal of Clinical Pediatric Dentistry 1999; 23: 357-9.

4. Erdogan F, Ismailogullari S, Soyuer I, et al. Different seizure types and skin lesions in oculocerebrorenal syndrome of Lowe. Journal of Child Neurology 2007; 22: 427-31.

\title{
Double inferior vena cava: beware!
}

\section{J D Arudchelvam, R M T M Gunawardena, L R Dissanayake, M R N Cassim, S M Wijeyaratne}

Ceylon Medical Journal 2013; 58: 38-39

\section{Introduction}

Double inferior vena cava (DIVC) is a congenital anomaly arising due to abnormal development of embryonic venous channels. It is rare with an incidence of $0.2 \%$ to $3 \%$ percent $[1,2]$. Its non recognition may result in diagnostic and surgical errors. Modern imaging with CT and MR has simplified its detection [3]. We report one such case to illustrate how it can be useful to know of its presence.

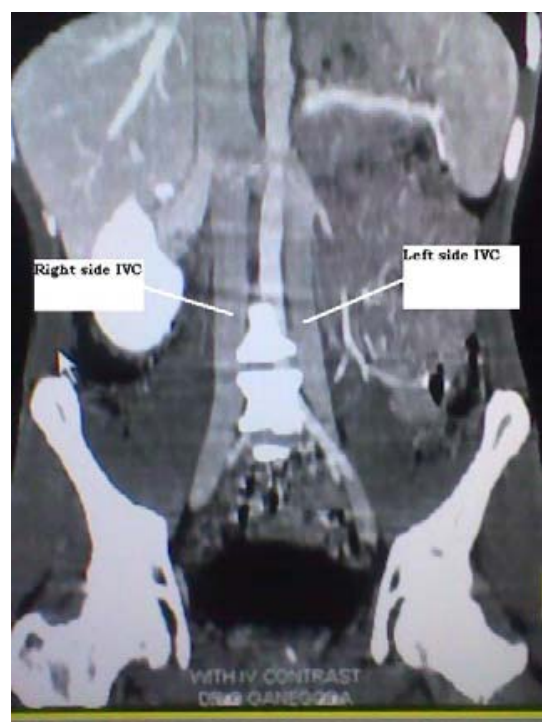

\section{Case report}

A 27-year old male was found to have infrarenal DIVC during evaluation for living kidney donation. The IVC was seen on either side of the abdominal aorta. He had normal IVC on right side and an abnormal IVC on the left side of aorta. The left renal vein was draining into left IVC (Figures 1 and 2). Left kidney was harvested. Patient

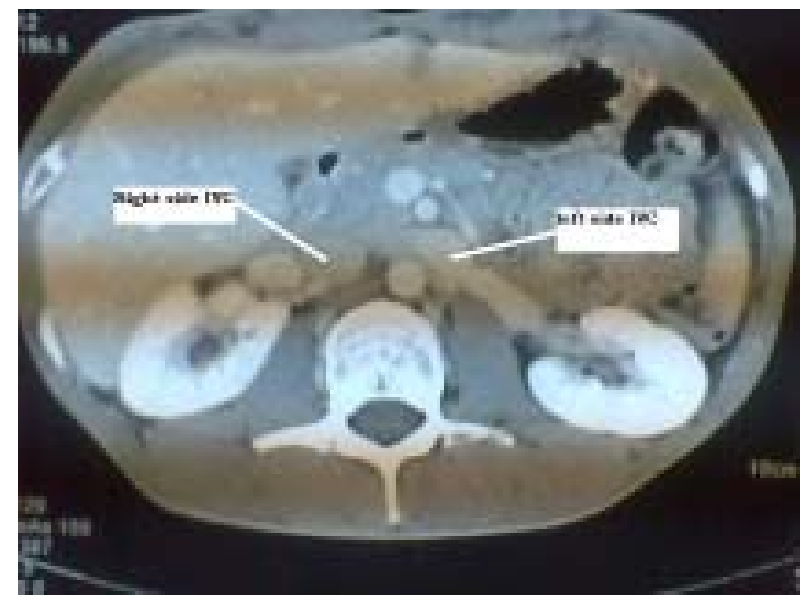

Figure 2.

Figure 1.

University Surgical Unit, National Hospital, Colombo, Sri Lanka.

Correspondence: JDA, e-mail: <joelaru@yahoo.com>. Received 21 June and revised version accepted 11 October 2012. Competing interests: none declared. 
had an uneventful post operative period.

\section{Discussion}

During early fetogenesis venous drainage from the left and right sides are independent. Subsequent regression of the majority of left sided sub and supracardinal veins and interconnection between sacrocardinal veins, that directs the entire left lower extremity venous drainage to the right side, results in the IVC as we know it in adult life [4]. What remains as a longitudinal vein on the left is the left gonadal vein.

In rare instances when the venous drainage from the left lower extremity and the retroperitoneum remains separated from the right side, the usually small caliber left gonadal vein presents itself as an equivalent to the IVC on the left side. This channel constitutes the entire venous drainage of the left lower extremity and should be protected from inadvertent injury during nephrectomy for cancers or donation, two instances where maximal venous dissection upto the cava is warranted.

Similarly a left sided IVC may get sacrificed during radical retroperitoneal dissections for cancers if its existence was not appreciated beforehand [5]. Furthermore such a cava may be mistaken for an obstructed left ureter if this developmental anomaly is overlooked [3]. Finally an infrarenal caval filter will not be effective in the case of venous thromboembolism from the left lower extremity. In such instances the filter should be placed below the left renal vein entry to the left sided cava [4].

Thus lack of awareness of this rare venous anomaly may result in serious diagnostic, surgical and therapeutic errors. This can easily be avoided by its recognition in MR and CT imaging.

\section{References}

1. Masood J, Barua JM. Images in clinical medicine. Duplication of the inferior vena cava. New England Journal of Medicine 2007; 356: e17.

2. Bass JE, Redwine MD, Kramer LA, Huynh PT, Harris JH Jr. Spectrum of congenital anomalies of the inferior vena cava: cross-sectional imaging findings. Radiographics 2000; 20: 639-52.

3. Ng WT, Ng SSM. Double inferior vena cava: a report of three cases. Singapore Medical Journal 2009; 50: e211-3.

4. Singh I. Cardiovascular System. In: Singh I; ed. Human Embryology. 6th ed. Macmillan India Limited; 1996: 212-60.

5. Shingleton WB, Hutton M, Resnick MI. Duplication of inferior vena cava: its importance in retroperitoneal surgery. 